\title{
Serum potassium level used as trigger doubled the detection of adverse drug events when compared with calcium polystyrene sulfonate trigger: a cross- sectional study
}

\author{
Patricia de Carvalho Mastroianni ${ }^{1}$ (D), Marina Vieira Borges $^{1}$ (D), Marcela Forgerini ${ }^{1}$ (D), \\ Tales Rubens de Nadai ${ }^{2}$ (D), Fabiana Rossi Varallo ${ }^{3 *}$ (1) \\ ${ }^{1}$ Department of Drugs and Medicines, School of Pharmaceutical Sciences, São Paulo State University (UNESP), Araraquara, SP, \\ Brazil \\ ${ }^{2}$ Department of Public Health, Bauru School of Dentistry, University of São Paulo (USP), Bauru, SP, Brazil \\ ${ }^{3}$ University of São Paulo, Ribeirão Preto Faculty of Pharmaceutical Sciences, Ribeirão Preto, SP, Brazil \\ *Corresponding author: frvarallo@fcfrp.usp.br
}

\begin{abstract}
Background: Prescription of calcium polystyrene sulfonate (CPS) has been considered a trigger with good performance to detect hyperkalemia related to adverse drug events (ADE). However, CPS prescription may underestimate the rate of $A D E$. Objective: To compare the performance of the serum potassium level $(\mathrm{SPL})>5.0 \mathrm{mEq} / \mathrm{L}$ and $\mathrm{CPS}$ triggers in detecting hyperkalemia related to $\mathrm{ADE}$. Design and setting: A six-month cross-sectional study was conducted in a Brazilian mediumcomplexity public hospital. Methods: SPL Tests with results $>5.0 \mathrm{mEq} / \mathrm{L}$ and the prescriptions of CPS of all patients hospitalized in the internal medicine and infectious diseases wards were used as trigger tools to detect potential ADE. Primary outcome: patients with hyperkalemia related to ADE. Secondary outcomes: effectiveness of treatments and ADE. Variables analyzed were SPL tests, CPS prescriptions, treatments of hyperkalemia and comorbidities. Positive predictive values (PPV) of CPS and SPL triggers were calculated and compared. Results: In total 2,466 SPL tests were assessed, of which 513 were triggered $(>5.0 \mathrm{mEq} / \mathrm{L})$. The tests triggered 198 patients with hyperkalemia, of whom 121 had hyperkalemia related to ADE (PPV=0.61). In total, 101 CPS prescriptions triggered tests in 35 patients with hyperkalemia, among whom 21 cases were related to ADE (PPV=0.60). SPL detected 204 ADE (PPV=0.40), while CPS prescription detected 22 (PPV=0.21). Seven pharmacological and four non-pharmacological treatments were identified. CPS showed the lowest effectiveness (PPV=0.71). Conclusion: SPL $>5.0 \mathrm{mEq} / \mathrm{L}$ increased the detection of ADE by $9.3-$ fold, the number of patients tracked with hyperkalemia related to ADE by 5.8 -fold, and doubled the performance in detection of $A D E$ in comparison with the prescription of the CPS trigger.
\end{abstract}

Keywords: Drug Monitoring. Outcome Assessment. Drug-Related Side Effects and Adverse Reactions. Hyperkalemia. Safety Management.

\section{How to cite}

Mastroianni PC, Vieira MB, Forgerini M, Nadai TR, Varallo FR. Serum potassium level used as trigger doubled the detection of adverse drug events when compared with calcium polystyrene sulfonate trigger: a cross-sectional study. Rev Ciênc Farm Básica Apl. 2021;42:e724.

https://doi.org/10.4322/2179-443X.0724

Funding source: Programa Institucional de Bolsas de Iniciação Científica (PIBIC 2018; Funding Number: 45918) and The São Paulo Research Foundation FAPESP (Funding Number 2018/07501-9). This study was financed in part by the Coordenação de Aperfeiçoamento de Pessoal de Nível Superior - Brasil (CAPES) - Finance Code 001.

Conflicts of interest: The authors declared no conflict of interest.

The study was carried out at Hospital Estadual Américo Brasiliense.

Received on February 18, 2021. Accepted on March 26, 2021. 


\section{INTRODUCTION}

Pharmacovigilance is defined as the science of and activities related to the detection, assessment, understanding and prevention of adverse effects or any other possible drugrelated problems ${ }^{1}$. The primary aim of assessment of safety and effectiveness of drugs is to avoid or prevent adverse drug events (ADE) when the drugs are available on the pharmaceutical market. ADE is an injury resulting from medical intervention related to a drug $^{2}$.

In 2003, the Institute for Healthcare Improvement (IHI) suggested 24 trigger tools for detecting $\mathrm{ADE}^{3}$. A trigger tool is defined as an occurrence (flag or prompt) easily recognized in the medical record to alert the reviewer about a potential $A D E$, which may not have been identified ${ }^{4}$.

This technique has been shown to be more practical and less laborious for detecting ADE $E^{3,5}$ when compared with retrospective analysis of medical records, which is more expensive and requires more time ${ }^{6}$. Furthermore, active surveillance with the aid of trigger tools is more effective in hospitals since the method can identify ten times more ADE when compared with spontaneous ADE reporting? .

Among the medications, laboratory parameters, information about the care and clinical outcome considered trigger tools by $\mathrm{IH}^{3}$, sodium polystyrene sulfonate (SPS) is applied to detect potential drug-induced hyperkalemia and kidney impairment ${ }^{3}$. The presence of two out of three triggers screened by means of using SPS is considered representative of the existence of definite or probable ADE, which makes SPS a trigger tool with good performance ${ }^{8}$. However, there are several safety concerns about SPS use in clinical practice, such as: occurrence of serious gastrointestinal disorders ${ }^{9}$, poor tolerability and uncertainty regarding its efficacy ${ }^{10}$. For this reason, the use of SPS is increasingly being replaced by the use of new potassium binders (patiromer and zirconium), which potentially have a better safety profile than SPS ${ }^{10}$.

In this context, it is important to highlight that in Brazilian hospitals the calcium polystyrene sulfonate (CPS) is selected and acquired instead of SPS, because CPS is the only potassium binder approved by Brazilian Health Regulatory Agency (ANVISA).

Normalization of serum potassium level (SPL) can be accomplished by nonpharmacological approaches (reducing potassium intake from external sources, or discontinuing with or reducing doses of hyperkalemia-inducing medicines); shifting potassium from the blood into the cells (temporizing agents such as salbutamol, insulin/dextrose or sodium bicarbonate); and increasing potassium removal from the body [e.g. use of potassium binding agents (CPS, SPS, patiromer, zirconium cyclosilicate), furosemide, dialysis] or a combination of these methods ${ }^{11}$.

A systematic review identified 23 different pharmacotherapies, other than SPS or CPS, available for the management of hyperkalemia ${ }^{12}$. At present, there is no guideline available for managing hyperkalemia, and the pharmacotherapy used is based on clinical experience and off-label use. The physician's choice of the drug will depend on clinical evaluation of the patient and safety profile of the therapies available in the healthcare services ${ }^{13}$.

Hyperkalemia related to ADE is known to be the most important cause of increased potassium levels found in patients, in daily clinical practice ${ }^{14}$ and the detection of ADE with the aid of SPS or CPS trigger tools could lead to underestimating the rate of cases $^{13}$. In this setting, to improve the prevention, detection and resolution of hyperkalemia related to $A D E^{13}$, this study aimed to assess the performance of $\mathrm{SPL}>5.0 \mathrm{mEq} / \mathrm{L}$ in detecting $\mathrm{ADE}$ in comparison with the standard trigger tool CPS.

\section{METHODS}

\section{Study design and setting}

This six-month (June to November, 2018) cross-sectional study was conducted in a Brazilian medium-complexity public hospital with 30 clinical and surgical specialties and 104 beds. 
The variables of interest were recorded on a daily basis for six months. The hospital had an electronic recording system, including records of prescriptions, clinical conditions and laboratory tests.

\section{Participants, study size and data collection}

All patients aged $>18$ years old admitted to internal medicine and infectious diseases wards, with SPL > $5.0 \mathrm{mEq} / \mathrm{L}$ (hyperkalemia) ${ }^{15}$ were enrolled, as well as those who received prescriptions of CPS.

The tests of SPL $>5.0 \mathrm{mEq} / \mathrm{L}$ may trigger the same patient several times, which may indicate readmission to the hospital, recurrence of a disturbance or monitoring of the resolution of electrolytic disturbance during the same length of stay in hospital. Thus, an average of 2.7 tests of SPL/day were analyzed.

After recruitment of participants, the patients triggered with hyperkalemia were assessed in order to detect if the electrolytic disturbance was related to $A D E$, or not.

Therefore, medical history, SPL tests, CPS prescription and other pharmacological and nonpharmacological treatments of hyperkalemia were reviewed daily, according to assistance protocol (Figure 1).

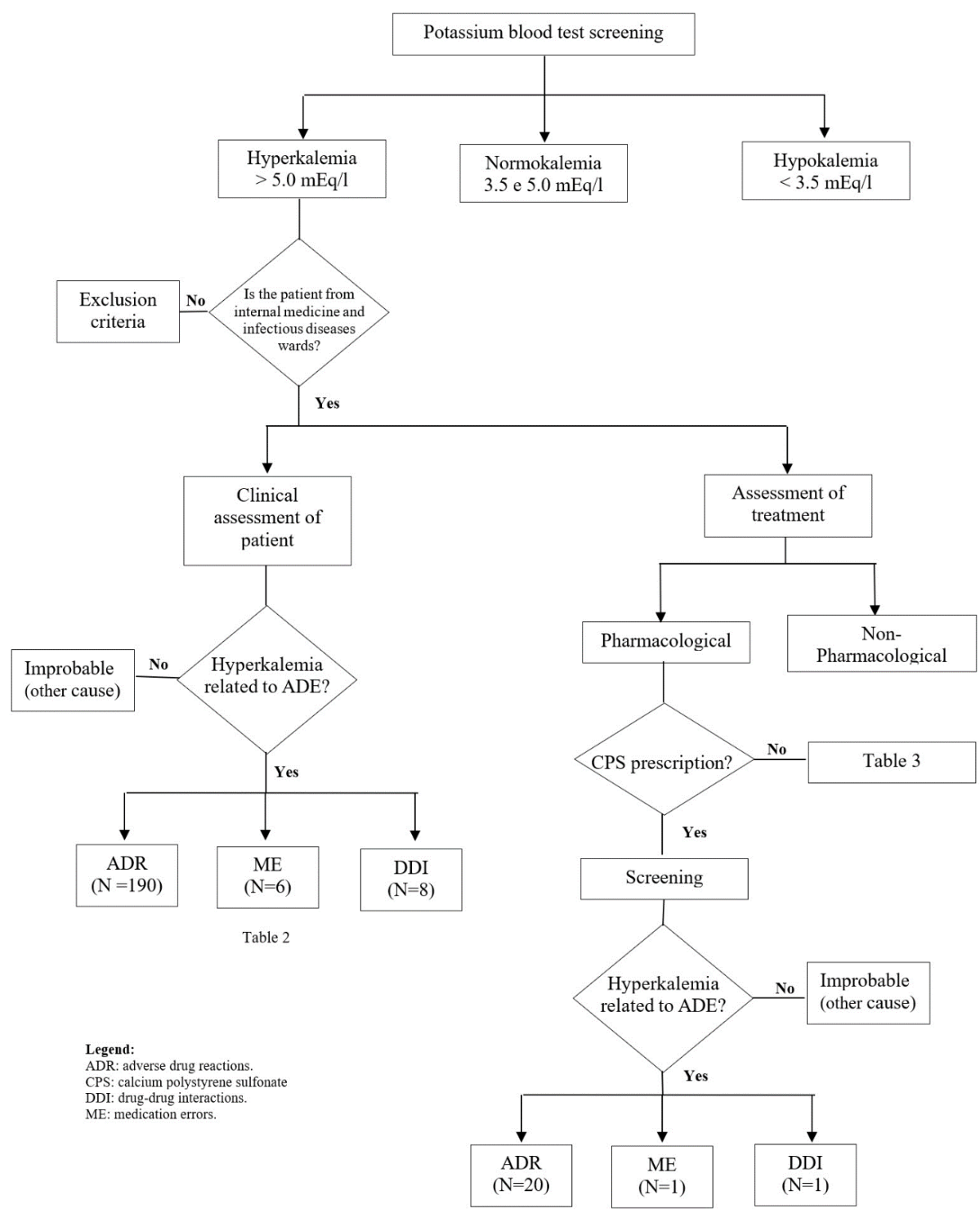

Figure 1. Flowchart of assistance protocol. 
Follow-up was performed to assess causal association and the clinical outcomes: hyperkalemia related to $A D E$ [adverse drug reaction (ADR), therapeutic failure (TF), medication errors (ME) and drug-drug interactions (DDI)] (Figure 1); and the effectiveness of pharmacological and non-pharmacological treatments of hyperkalemia.

The parameters to monitor the effectiveness of the treatment of hyperkalemia included SPL tests that showed normokalemia ( $3.5 \mathrm{mEq} / \mathrm{L}$ to $5.0 \mathrm{mEq} / \mathrm{L})$ or mild hyperkalemia without clinical relevance $(5.1 \mathrm{mEq} / \mathrm{L}$ to $5.5 \mathrm{mEq} / \mathrm{L})$. SPL $<3.5 \mathrm{mEq} / \mathrm{L}$ were also analyzed to identify possible poisoning or hypersensitivity to the pharmacotherapy prescribed for managing the electrolytic disturbance (Figure 1).

\section{Variables, data sources and measurements}

Patients with hyperkalemia related to ADE were the primary outcome. Secondary outcomes consisted of quantity of SPL tests $>5 \mathrm{mEq} / \mathrm{L}$, number of CPS prescriptions related to hyperkalemia due to $A D E$, and the evidence of parameters of effectiveness of pharmacological and non-pharmacological treatments of hyperkalemia.

The patients triggered by SPL tests $>5 \mathrm{mEq} / \mathrm{L}$ and CPS prescriptions were tracked for detecting ADE. Thus, demographic characteristics, clinical conditions and pharmacotherapies prescribed were assessed (Table 1).

Table 1. Variables analyzed, data sources, and measurement.

\begin{tabular}{|c|c|}
\hline Variables & Data sources/measurement \\
\hline Clinical conditions & Morbidity and comorbidities described in patient record charts \\
\hline \multirow{2}{*}{ 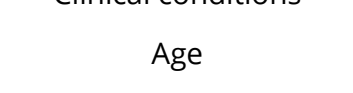 } & Older people and adults \\
\hline & Patients 60 years or older were considered elderly \\
\hline Polypharmacy & 4 or more drugs, according to the World Health Organization ${ }^{22}$ \\
\hline Hyperkalemia & $\begin{array}{l}\text { Mild }(5.1 \mathrm{mEq} / \mathrm{L}<x<5.5 \mathrm{mEq} / \mathrm{L}) \text {, moderade }(5.6 \mathrm{mEq} / \mathrm{L}<x<6.0 \mathrm{mEq} / \mathrm{L}) \\
\text { and serious }(>6.0 \mathrm{mEq} / \mathrm{L})^{15}\end{array}$ \\
\hline $\begin{array}{l}\text { Trigger } 1: \text { Serum } \\
\text { potassium level }\end{array}$ & $\begin{array}{l}\text { Normokalemia ( } 3.5 \mathrm{mEq} / \mathrm{L} \text { to } 5,0 \mathrm{mEq} / \mathrm{L}) \text {, hyperkalemia (> } 5.0 \mathrm{mEq} / \mathrm{L} \text { ) and } \\
\text { hypokalemia (<3.5 mEq/L) }\end{array}$ \\
\hline $\begin{array}{l}\text { Trigger } 2 \text { : calcium } \\
\text { polystyrene sulfonate } \\
\text { prescription }\end{array}$ & Calcium polystyrene sulfonate prescription \\
\hline Treatments & Pharmacological and non-pharmacological \\
\hline Pharmacological & $\begin{array}{l}\text { Drugs and combined pharmacotherapy prescribed for management of } \\
\text { hyperkalemia, including calcium polystyrene sulfonate prescription }\end{array}$ \\
\hline Non-pharmacological & $\begin{array}{l}\text { Withdrawal of suspect drug, low-potassium diet, administration of fluids } \\
\text { and hemodialysis }\end{array}$ \\
\hline Primary outcome & Drug-induced hyperkalemia \\
\hline $\begin{array}{l}\text { Hyperkalemia related to } \\
\qquad \text { ADE }\end{array}$ & $\begin{array}{l}\text { Definite, probable or possible adverse drug reaction (ADR) } \\
\text { ADR: any noxious, unintended, or undesired effect of a drug occurring at } \\
\text { doses used in humans for prophylaxis, diagnosis, or therapy }{ }^{24}\end{array}$ \\
\hline \multirow{2}{*}{$\begin{array}{l}\text { Hyperkalemia unrelated } \\
\text { to } A D E\end{array}$} & Improbable ADR \\
\hline & Confounding factors: morbidity, age, kidney impairment \\
\hline \multirow{2}{*}{$\begin{array}{l}\text { Secondary outcome } \\
\text { Evidence of parameters } \\
\text { of the effectiveness of } \\
\text { treatments }\end{array}$} & Adverse drug events and performance of treatment effectiveness \\
\hline & $\begin{array}{l}\text { Normokalemia ( } 3.5 \mathrm{mEq} / \mathrm{L} \text { to } 5.0 \mathrm{mEq} / \mathrm{L}) \text { or mild hyperkalemia without } \\
\text { clinical relevance }(5.1 \mathrm{mEq} / \mathrm{L} \text { to } 5.5 \mathrm{mEq} / \mathrm{L}) \text {. }\end{array}$ \\
\hline \multicolumn{2}{|r|}{ Adverse drug events (ADE) } \\
\hline Adverse drug reaction & WHO-UMC algorithm 8,25 \\
\hline Drug-drug interaction & $\begin{array}{l}\text { Suggestive of poisoning by hyperkalemia treatment, detected by PBT } \\
\text { with serum potassium level }<3.5 \mathrm{mEq} / \mathrm{L}\end{array}$ \\
\hline Therapeutic failure & $\begin{array}{l}\text { Treatments that did not archive normokalemia or mild hyperkalemia } \\
\text { without clinical relevance }\end{array}$ \\
\hline Medication errors & $\begin{array}{l}\text { Off-label use, noncompliance of pharmacotherapy, drug-drug } \\
\text { interactions related to hyperkalemia } 26\end{array}$ \\
\hline
\end{tabular}


The causality assessment was performed by using clinical judgment. The clinical pharmacist of the hospital supervised the researcher responsible for the imputation of ADE. The judge was a pharmacy undergraduate student who was previously trained to standardize the analysis of causal association. The training took into account the drugs often associated with hyperkalemia and the contributing factors related to health conditions, polypharmacy (to investigate drug-drug interaction) and off-label use (to investigate medication errors and therapeutic failure). Practical classes consisted of causality assessment, with analysis of fictitious ADRs to be imputed.

Positive predictive values (PPV) of CPS prescriptions and SPL $>5 \mathrm{mEq} / \mathrm{L}$ were calculated to compare performance of the triggers in detecting primary and secondary outcomes. Therefore, the formulas applied for calculations were:

a) Primary outcome

- hyperkalemia related to ADE:

$P P V=\frac{\text { number of inpatients with hyperkalemia related to ADE in the period }}{\text { number of inpatients tracked by the tool in the period }}$

b) Secondary outcomes

- ADE detection:

$P P V=\frac{\text { number of } A D E \text { detected by the tool in the period }}{\text { number of times that the tool was triggered in the period }}$

- Effectiveness of pharmacological and non-pharmacological treatment of hyperkalemia:

$P P V=\frac{\text { number of inpatients } \text { who recieved the treatment, with parameter of evidence of effectiveness }}{}$ total number of inpatients that recieved the same treatment

\section{Statistical methods}

A descriptive statistics analysis was performed for SPL tests; CPS prescriptions; demographic characteristics (i.e., sex and age); treatments, and ADE.

The Chi-square test was applied to assess association between sex, aging, polypharmacy and hyperkalemia related to $A D E$, and to verify whether there was statistically significance difference between the PPV of the triggers evaluated (serum potassium level $>5.0 \mathrm{mEq} / \mathrm{L}$ and CPS prescriptions) and type of treatment (pharmacological and non-pharmacological) to manage hyperkalemia related to ADE and hyperkalemia unrelated to ADE.

The odds ratio (OR) was calculated to assess whether sex, aging and polypharmacy were considered risk factors for the occurrence hyperkalemia related to ADE. The one-way ANOVA statistical test was applied to verify whether there was statistically significance difference between patients with hyperkalemia related to ADE or hyperkalemia unrelated to ADE, according to comorbidities and treatment to manage the electrolytic disturbance (pharmacological and non-pharmacological and non-treatment). In all statistical tests, significance was accepted when p-value $<0.05$.

\section{Research ethics committee}

This study was conducted in accordance with Declaration of Helsinki and was approved by the Ethics Committee of the Universidade Paulista (UNIP) and the Committee of Medical Record Review (protocol CAAE 00228918.8.0000.5512). 


\section{RESULTS}

During this study, there were 2,259 hospital admissions of 2,045 patients in the internal medicine and infectious diseases wards.

In total, 2,466 tests of SPL were performed and 513 of these were triggered $(>5.0 \mathrm{mEq} / \mathrm{L})$. Considering the 513 tests triggered, 198 patients with hyperkalemia were tracked and 121 of them (61.1\%) had at least one ADE (hyperkalemia related to ADE). While a patient was being monitored, an average of two to three SPL tests were conducted, which justified a higher number of tests than patients (Figure 2).

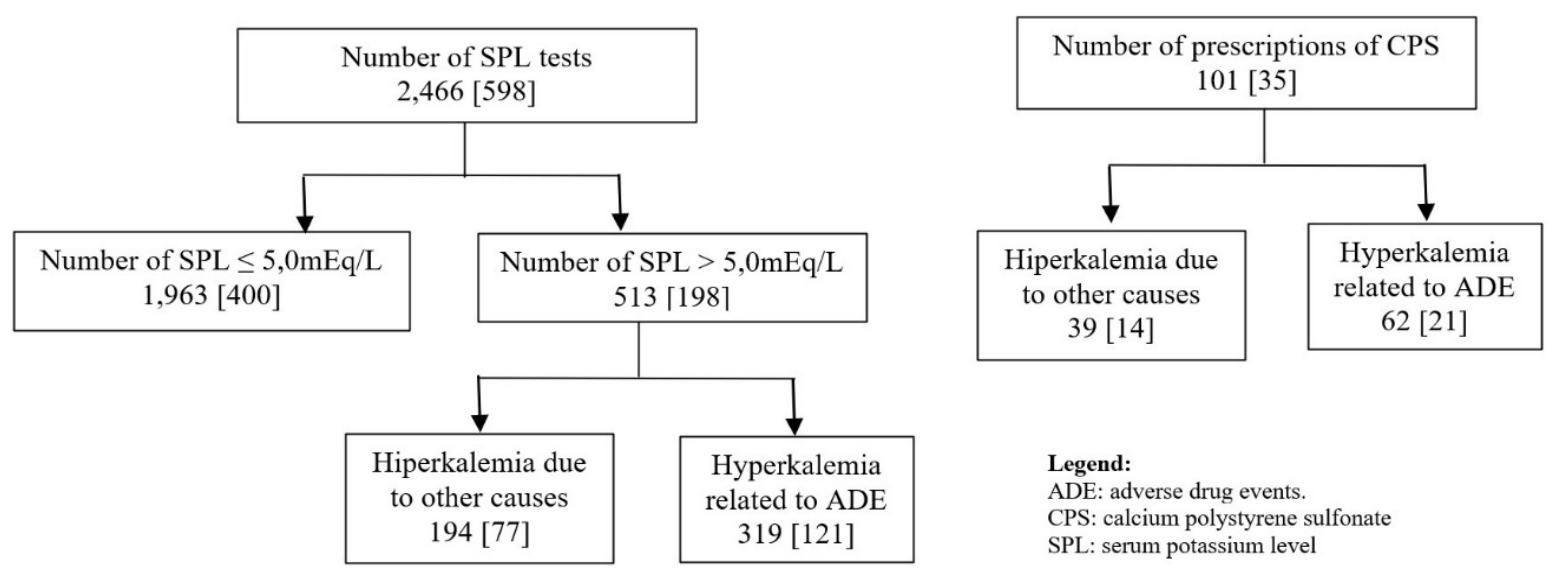

Figure 2. Flowchart of the screening and detection of hyperkalemia related to ADE among inpatients [n] hospitalized at internal medicine and infections wards.

From another perspective, 101 CPS prescriptions were identified and of these, 62 were prescribed for the management of hyperkalemia. This data corresponded to 35 patients triggered by CPS prescriptions, of whom 21 [60,0\% (21/35)] developed hyperkalemia related to ADE (Figure 2).

Data showed that SPL $>5.0 \mathrm{mEq} / \mathrm{L}$ increased the possibility of identifying patients with hyperkalemia (related to ADE and unrelated to ADE) by 5.7-fold (198/35), and the detection of patients with hyperkalemia related to ADE by 5.8 -fold (121/21), when compared with CPS trigger (Figure 2).

Both tools to trigger patient with hyperkalemia related to ADE showed a similar performance, since PPV of SPL was 0.61 (121/198) and PPV of CPS was $0.60(21 / 35)$. However, when we considered the quantity of SPL tests $>5.0 \mathrm{mEq} / \mathrm{L}$ and the number of CPS prescriptions associated with hyperkalemia related to $A D E$, the SPL trigger was observed to double the efficiency of detection of ADE [PPV=0.40 (204 ADE/ 513 exams)], when compared with the CPS prescriptions [PPV $=0.21$ (22 ADE /101 prescriptions)].These findings showed that the SPL trigger increased the detection of ADE by 9.3-fold (204/22) (190 ADR, six medication errors and eight drug-drug interactions) due to different options of pharmacological treatments, thus exceeding CPS.

Sex $(p=0.122)$, polypharmacy $(p=0.545)$ and aging $(p=0.447)$ were not identified as risk factors for occurrence of hyperkalemia related to ADE. In addition, no statistically significant difference was observed between comorbidities $(p=0.651)$, treatments prescribed for management of hyperkalemia $(p=0.233)$ and performance of trigger tools $(p=0.841)$ between patients with hyperkalemia related to $A D E$ and patients with hyperkalemia unrelated to ADE.

Nineteen drugs related to the occurrence of hyperkalemia were identified, with the most frequent being: heparin, enalapril and, spironolactone (Table 2), since the most prevalent comorbidities were associated with metabolic and cardiovascular diseases. 
Table 2. Drugs and frequency of patients with adverse drug events (ADE) and adverse drug reactions (ADR) detected by test of serum potassium level and calcium polystyrene sulfonate (CPS) prescription triggers according to Anatomical Therapeutic Chemical (ATC) classification system code, frequency and type of ADE and causality of ADR.

\begin{tabular}{|c|c|c|c|c|c|c|c|}
\hline \multirow{3}{*}{ Drug (ATC) } & \multirow{3}{*}{$\begin{array}{c}\text { ADE } \\
\mathrm{N}(\%) \\
\end{array}$} & \multicolumn{3}{|c|}{ ADR causality } & \multirow{3}{*}{$\begin{array}{c}\mathrm{ME} \\
\mathbf{N} \\
\end{array}$} & \multirow{3}{*}{$\begin{array}{c}\mathrm{DDI} \\
\mathbf{N} \\
\end{array}$} & \multirow{3}{*}{$\begin{array}{c}\text { Patients } \\
\mathbf{N}(\%) \\
\end{array}$} \\
\hline & & & $\mathbf{N}$ & & & & \\
\hline & & Definite & Probable & Possible & & & \\
\hline $\begin{array}{l}\text { Heparin } \\
\text { (B01AB01) }\end{array}$ & $\begin{array}{c}66 \\
(32.4)\end{array}$ & 0 & 13 & 52 & $1^{a}$ & 0 & $65^{a}(32.8)$ \\
\hline $\begin{array}{l}\text { Enalapril } \\
\text { (CO9AA02) }\end{array}$ & $\begin{array}{c}25 \\
(12.3)\end{array}$ & 0 & 11 & 11 & 2 & $1^{\mathrm{a}}$ & $24^{a}(12.1)$ \\
\hline $\begin{array}{l}\text { Spironolactone } \\
\text { (C03DA01) }\end{array}$ & $\begin{array}{c}24 \\
(11.8)\end{array}$ & 1 & 8 & 14 & 0 & $1^{\mathrm{a}}$ & $23(11.6)$ \\
\hline $\begin{array}{l}\text { Losartan } \\
\text { (C09CA01) }\end{array}$ & $20(9.8)$ & 0 & 10 & 8 & 1 & 1 & $20(10.1)$ \\
\hline $\begin{array}{l}\text { Acid acetylsalicylic } \\
\text { (B01AC06) }\end{array}$ & $14(6.9)$ & 0 & 4 & 8 & 0 & 2 & $14(7.1)$ \\
\hline $\begin{array}{c}\text { Atenolol } \\
\text { (C07AB03) }\end{array}$ & $12(5.9)$ & 0 & 2 & 10 & 0 & 0 & $12(6.1)$ \\
\hline $\begin{array}{l}\text { Potassium chloride } \\
\text { (A12BA01) }\end{array}$ & $9(4.4)$ & 1 & 4 & 2 & $1^{a}$ & $1^{\mathrm{a}}$ & $7(3.5)$ \\
\hline $\begin{array}{l}\text { Carvedilol } \\
\text { (C07AG02) }\end{array}$ & $7(3.4)$ & 1 & 2 & 3 & 0 & 1 & $7(3.5)$ \\
\hline $\begin{array}{l}\text { Metoprolol } \\
\text { (C07AB02) }\end{array}$ & $6(2.9)$ & 0 & 0 & 6 & 0 & 0 & $6(3.0)$ \\
\hline $\begin{array}{l}\text { Propranolol } \\
\text { (C07AA05) }\end{array}$ & $5(2.5)$ & 0 & 2 & 1 & 1 & $1^{\mathrm{a}}$ & $4(2.0)$ \\
\hline $\begin{array}{c}\text { Captopril } \\
\text { (C09AA01) }\end{array}$ & $4(2.0)$ & 0 & 0 & 4 & 0 & 0 & $4(2.0)$ \\
\hline $\begin{array}{l}\text { Potassium phosphate } \\
\text { (B05XA06) }\end{array}$ & $3(1.5)$ & 0 & 2 & 1 & 0 & 0 & $3(1.5)$ \\
\hline $\begin{array}{c}\text { Saccharomyces } \\
\text { boulardii } \\
\text { (A07FA02) }\end{array}$ & $2(1.0)$ & 0 & 0 & 2 & 0 & 0 & $2(1.0)$ \\
\hline $\begin{array}{l}\text { Valsartan } \\
\text { (C09CA03) }\end{array}$ & $2(1.0)$ & 0 & 0 & 2 & 0 & 0 & $2(1.0)$ \\
\hline $\begin{array}{l}\text { Codeine } \\
\text { (R05DA04) }\end{array}$ & $1(0.5)$ & 0 & 0 & 1 & 0 & 0 & $1(0.5)$ \\
\hline $\begin{array}{l}\text { Supplement } \\
\text { (A12) }\end{array}$ & $1(0.5)$ & 0 & 1 & 0 & 0 & 0 & $1(0.5)$ \\
\hline $\begin{array}{l}\text { Vancomycin } \\
\text { (J01XA01) }\end{array}$ & $1(0.5)$ & 0 & 1 & 0 & 0 & 0 & $1(0.5)$ \\
\hline $\begin{array}{l}\text { Prednisone } \\
\text { (H02AB07) }\end{array}$ & $1(0.5)$ & 0 & 0 & 1 & 0 & 0 & $1(0.5)$ \\
\hline $\begin{array}{l}\text { Ketoprofen } \\
\text { (M01AE03) }\end{array}$ & $1(0.5)$ & 0 & 0 & 1 & 0 & 0 & $1(0.5)$ \\
\hline Detected by PBT & $\begin{array}{c}204 \\
(100.0)\end{array}$ & $3(1.5)$ & $60(29.4)$ & $\begin{array}{c}127 \\
(62.3)\end{array}$ & $\begin{array}{c}6 \\
(2.9)\end{array}$ & $\begin{array}{c}8 \\
(3,9)\end{array}$ & $121(100.0)$ \\
\hline Detected by CPS & $\begin{array}{c}22 \\
(100.0)\end{array}$ & $1(4.5)$ & $7(31.8)$ & $12(54.5)$ & $\begin{array}{c}1 \\
(4.5)\end{array}$ & $\begin{array}{c}1^{\mathrm{a}} \\
(4,5)\end{array}$ & $21(100.0)$ \\
\hline TOTAL & 204 & 3 & 60 & 127 & 6 & 8 & 121 \\
\hline
\end{tabular}

Abbreviations: ATC: Anatomical Therapeutic Chemical; ADE: adverse drug event; ADR: adverse drug reaction; ME: medication errors; DDI: drug-drug interactions; PBT: potassium blood test; CPS: calcium polystyrene sulfonate. ${ }^{\text {a }}$ patient may develop drug-induced hyperkalemia associated with more than one ADE.

For the management of hyperkalemia, pharmacological treatment was the most common type applied. Furosemide and beta-agonist (fenoterol) + muscarinic antagonist (ipratropium) were more frequently prescribed than CPS and polarizing solution (Table 3), justifying the lower number of patients with ADE detected by CPS prescriptions when compared with SPL $>5.0 \mathrm{mEq} / \mathrm{L}$. 
Table 3. Frequency of patients $(\mathrm{N})$ who received pharmacological and non-pharmacological treatment for hyperkalemia management, according to etiology of the electrolytic disturbance (drug-induced or non-drug-induced).

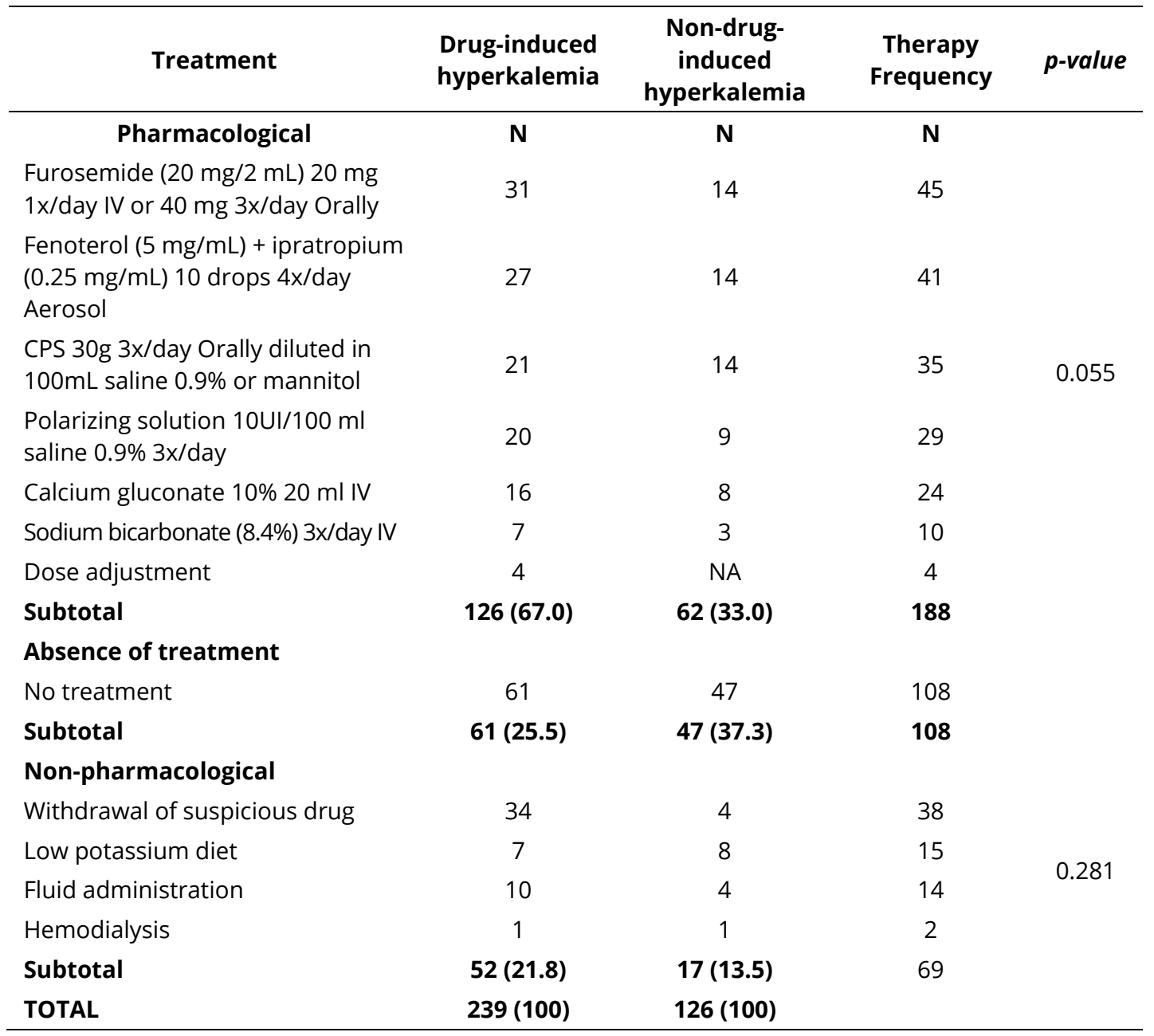

Abbreviations: mg: milligrams; $\mathrm{mL}$ : milliliters; CPS: calcium polystyrene sulfonate; IV: intravenous; NA: not applicable. In total, 365 treatments were monitored since several patients received more than one prescription of pharmacological and/or non-pharmacological prescriptions (median of 1.8 treatment per patient).

Although furosemide was the drug of first choice in the hospital under study, according to the evidence of parameters effectiveness, its performance (PPV= 0.82) was lower in comparison with that of polarizing solution (PPV=0.93) (Table 4).

Among the 35 patients who received treatment by administration of CPS, only 25 achieved normokalemia or mild hyperkalemia without clinical relevance. Thus, the treatment with CPS was the less effective (PPV= 0.71) when compared with other options available (Table 4). In addition, one patient refused to take the CPS due to a complaint of constipation.

Follow-up and monitoring of hyperkalemia cases allowed the identification of 24 treatments for the management of hyperkalemia with inconclusive effectiveness, since there was no SPL test showing normokalemia. In two other cases, the treatment was discontinued before the parameters of effectiveness were achieved.

A hundred and eight patients did not receive any type of treatment for the management of hyperkalemia (Table 3). This finding explained the detection of another 100 patients with hyperkalemia related to ADE detected by $\mathrm{SPL}>5.0 \mathrm{mEq} / \mathrm{L}$ and were undetected by the CPS trigger.

The non-pharmacological treatments of hyperkalemia corresponded to withdrawal of the suspect drug $(55.1 \%)$, low-potassium diet, $(21.7 \%)$, administration of fluids $(20.3 \%)$, and hemodialysis (2.9\%) (Table 3). 
Table 4. Predictive positive value (PPV) of the effectiveness of treatments (pharmacological and nonpharmacological) prescribed for management of hyperkalemia (drug-induced and non-drug-induced).

\begin{tabular}{|c|c|c|c|c|}
\hline \multicolumn{5}{|c|}{ Effectiveness } \\
\hline & Frequency of effectiveness (\%) & $\begin{array}{l}\text { Patient who } \\
\text { received } \\
\text { treatment }(\mathbf{N})^{a}\end{array}$ & $\begin{array}{l}\text { Patient with } \\
\text { effective } \\
\text { treatment }(\mathrm{N}) \\
\mathrm{a}\end{array}$ & PPV \\
\hline & $\begin{array}{l}\text { Polarizing solution } 10 U \mathrm{I} / 100 \mathrm{ml} \\
\text { saline } 0.9 \% 3 \mathrm{x} / \text { day }(93.1)\end{array}$ & 29 & 27 & 0.93 \\
\hline & $\begin{array}{l}\text { Calcium gluconate } 10 \% \\
20 \mathrm{ml} \mathrm{IV} \mathrm{(91.7)}\end{array}$ & 24 & 22 & 0.92 \\
\hline & $\begin{array}{l}\text { Sodium bicarbonate }(8.4 \%) \\
\qquad 3 x / \text { day IV }(90.0)\end{array}$ & 10 & 09 & 0.90 \\
\hline \multirow[t]{5}{*}{$\begin{array}{l}\text { Pharmacological } \\
\qquad(\mathrm{N}=188) *\end{array}$} & $\begin{array}{c}\text { Fenoterol }(5 \mathrm{mg} / \mathrm{mL})+ \\
\text { ipratropium }(0.25 \mathrm{mg} / \mathrm{mL}) \\
10 \text { drops } 4 x / \text { day Aerosol }(85.4)\end{array}$ & 41 & 35 & 0.85 \\
\hline & $\begin{array}{c}\text { Furosemide }(20 \mathrm{mg} / 2 \mathrm{~mL}) 20 \mathrm{mg} \\
\text { 1x/day IV or } 40 \mathrm{mg} 3 x / \text { day Orally } \\
(82.2)\end{array}$ & 45 & 37 & 0.82 \\
\hline & Dose Adjustment (75.0) & 08 & 06 & 0.75 \\
\hline & $\begin{array}{c}\text { CPS } 30 \mathrm{~g} 3 \text { x/day Orally or diluted } \\
\text { in } 100 \mathrm{~mL} \text { saline } 0.9 \% \text { or mannitol } \\
\text { (71.4) }\end{array}$ & 35 & 25 & 0.71 \\
\hline & Hemodialysis (100.0) & 02 & 02 & 1.00 \\
\hline \multirow{3}{*}{$\begin{array}{l}\text { Non- } \\
\text { pharmacological } \\
(\mathrm{N}=69)\end{array}$} & Low potassium diet (86.7) & 15 & 13 & 0.87 \\
\hline & $\begin{array}{l}\text { Withdrawal of suspicious drug } \\
\qquad(84.2)\end{array}$ & 38 & 32 & 0.84 \\
\hline & Fluid administration (85.7) & 14 & 12 & 0.86 \\
\hline Total & $\begin{array}{l}\text { Total of patients who did not } \\
\text { receive any treatment }(\mathrm{N}=108)\end{array}$ & $\begin{array}{l}\text { Total of } \\
\text { patients who } \\
\text { received at } \\
\text { least one } \\
\text { treatment } \\
(N=90)\end{array}$ & $\begin{array}{c}\text { Total of } \\
\text { patients who } \\
\text { had } \\
\text { parameters of } \\
\text { effectiveness } \\
(\mathrm{N}=52)\end{array}$ & 0.58 \\
\hline
\end{tabular}

Abbreviations: UI: international unit; IV: intravenous; mg: milligrams; mL: milliliters; CPS: calcium polystyrene sulfonate; PPV: predictive positive value; IV: intravenous. ${ }^{a}$ The same patient recruited received more than one treatment more than once.

Confounding factors (or alternative causes) associated with improbable ADE (66 triggers) were associated with the clinical condition of patients: diabetes mellitus (28 events), cardiovascular diseases (16 events), kidney impairment (15 events), respiratory disorders (five events), parasitic infection (one event), and neoplasia (one event). In addition, chronic obstructive pulmonary disease; congestive heart failure and Chagas disease; heart failure and acute myocardial infarct were also confounding factors with decrease in the causal imputation of probable (four events) and possible (14 events) events.

\section{DISCUSSION}

The tests performed with SPL level $>5.0 \mathrm{mEq} / \mathrm{L}$ for screening patient hyperkalemia related to ADE are similar to those of the CPS trigger. However, our data suggested that the SPL test was more capable of detecting ADE and ME/DDI related to electrolytic disturbance, monitoring of the effectiveness of treatment for hyperkalemia, and prevention of the iatrogenic cascade. Therefore, $S P L>5.0 \mathrm{mEq} / \mathrm{L}$ may improve patient safety, risk management and communication of drugs. 
There are no publications of randomized clinical trials about the treatment of hyperkalemia due to the ethical issues related to non-treatment of a potentially fatal condition ${ }^{16}$. This fact explains the lack of guidelines in the literature and the variability of treatments related to hyperkalemia ${ }^{12}$. Furthermore, there is no consensus about the definition of hyperkalemia ${ }^{17}$, although levels above $5.0 \mathrm{mmol} / \mathrm{L}$ are associated with increased mortality, and a serum potassium level higher than $5.5 \mathrm{mmol} / \mathrm{L}$ is generally accepted as the level that requires immediate intervention ${ }^{18}$.

Hence, the choices of hyperkalemia treatment will depend on the drugs standardized for use in the hospital, clinical experience of physicians and seriousness of patient. Furthermore, moderate or severe hyperkalemia has also been defined inconsistently in the literature ${ }^{19}$. Consequently, there is a scarcity of evidence of superiority of effectiveness and safety of all options for the management of hyperkalemia ${ }^{12}$.

In this setting, the CPS trigger contributes to under-reporting hyperkalemia related to ADE, since it is incapable of screening electrolytic disturbance related to medications errors, drugdrug interactions, and ADR of other drugs used. This finding corroborates our suggestion that SPL tests are triggers that have shown better performance.

Varallo et al. (2017) described the confounding factors associated with the impairment of trigger tool performance in screening of $A D E$, and observed the same clinical conditions we noted with regard to the CPS trigger ${ }^{8}$. The authors highlight the relevance of healthcare professionals relative to recognizing the confounding factors that trigger detectors of high and low-specificity in the detection of ADE, such as SPL tests, in order to improve screening, contribute to patient safety, and to the risk management policies of health facilities.

Another advantage of the SPL trigger is the possibility of being able to monitor the effectiveness of treatments. Findings showed that the emergency physician care is effective for lowering potassium level to a safe but not necessarily a normal range ${ }^{16}$. Patients with inconclusive data about treatment effectiveness were identified, which can potentially be hazardous when associated with an underlying disorder that remains without treatment.

Nonetheless, the selection of pharmacological treatment for hyperkalemia should consider not only the effectiveness, but the potential occurrence of $\mathrm{ADE}^{17}$. Considering that the majority of patients with hyperkalemia related to ADE were treated with various pharmacological options, there is cascade iatrogenesis, since new drug prescriptions were issued to treat the undesirable effects of drugs ${ }^{20}$.

The management of ADE may include drug withdrawal, dose adjustments, the prescription of other pharmacological treatment ${ }^{21}$, hospitalization, and supportive or palliative care depending on its seriousness of the patient's condition. However, when an ADE is misinterpreted as a new clinical condition, an inappropriate prescribing cascade occurs ${ }^{20}$; that is, prescription of unnecessary pharmacotherapy, which can also be associated with worsening of the clinical condition. In this context, another advantage of SLP as a trigger in comparison with CPS prescriptions, is the possibility of identifying cases of cascade iatrogenesis since SLP may allow the withdrawal of the drug responsible for hyperkalemia or the proposal of risk management plans to prevent the electrolytic disturbance.

Furosemide, for instance, the first treatment option identified in this study, increases the elimination of potassium in urine, and is associated with a depletion of volume ${ }^{22}$. Therefore, furosemide should be used with caution in patients with renal impairment. Another example is polarizing solution that increases potassium uptake into muscle cells ${ }^{22}$ and may lead to hypoglycemia ${ }^{17}$. Therefore, patient safety is also an important aspect to be considered in the selection of hyperkalemia pharmacotherapy, in order to prevent cascade iatrogenesis.

A disadvantage of screening for hyperkalemia related to ADE with the SPL trigger tool is its high sensitivity and moderate specificity that imply a greater demand for time to evaluate the cases identified. Nevertheless, improvement in patient safety as well as prevention of harm and possible death, overcome the issue of the time required for analysis.

The main limitation of this study was the sample size, considering that the internal medicine ward and infectious diseases ward have 30 beds. Patients in the intensive care unit 
were excluded, mainly due to confounding factors associated with induced hyperkalemia unrelated to $A D E$, such as kidney function and pathophysiological conditions ${ }^{23}$. Review of the charts of critical patients may underestimate the detection of $A D E$, since it impairs the assessment of causality. Furthermore, only seven pharmacological and four nonpharmacological treatments were assessed due to the characteristics of patients, wards evaluated and institutional guidelines. This fact highlights the importance of each hospital assessing the hyperkalemia treatment, as well the ADE screening and monitoring with use of the SPL trigger.

\section{CONCLUSION}

Most cases of hyperkalemia triggered by SPL $>5.0 \mathrm{mEq} / \mathrm{L}$ (61.1\%) are related to at least one ADE. Despite the similar performance of the two triggers (PPV of SPL=0.61 and PPV of CPS $=0.60$ ), the SPL trigger increased the number of patients tracked with hyperkalemia related to ADE by 5.8-fold, the detection of ADE by 9.3-fold, and doubled the performance in detecting drug-induced harm.

CPS was the third option of pharmacological treatment for the management of hyperkalemia and showed the worst effectiveness among the drug therapies prescribed. Moreover, patients with electrolytic disturbance could also be managed with nonpharmacological treatments or even without any treatment. Thus, the detection of druginduced hyperkalemia with use of the CPS trigger might be associated with under-reporting of cases.

\section{ACKNOWLEDGMENTS}

The Authors thank the following financing agencies for their support: Programa Institucional de Bolsas de Iniciação Científica (PIBIC 2018; Funding Number: 45918) and The São Paulo Research Foundation - FAPESP (Funding Number 2018/07501-9). This study was financed in part by the Coordenação de Aperfeiçoamento de Pessoal de Nível Superior - Brasil (CAPES) - Finance Code 001.

\section{REFERENCES}

1. Kohn LT, Corrigan JM, Donaldson MS. To err is human: building a safer health system. Washington DC: National Academy Press, 2000.

2. World Health Organization. The importance of pharmacovigilance. Safety monitoring of medicinal products. Geneva: World Health Organization; 2002.

3. Rozich JD, Haraden CR, Resar RK. Adverse drug event trigger tool: a practical methodology for measuring medication related harm. Qual Saf Health Care. 2003;12(3):194-200. http://dx.doi.org/10.1136/qhc.12.3.194. PMid:12792009.

4. De Wet C, Bowie P. Screening electronic patient records to detect preventable harm: a trigger tool for primary care. Qual Prim Care. 2011;19(2):115-25. PMid:21575334.

5. Resar RK, Rozich JD, Simmonds T, Haraden CR. A trigger tool to identify adverse events in the intensive care unit. Jt Comm J Qual Patient Saf. 2006;32(10):585-90. http://dx.doi.org/10.1016/S1553-7250(06)32076-4. PMid:17066996.

6. Rozenfeld S, et al. Adverse effects from drugs in a public hospital: pilot study. Rev Saude Publica. 2009;43(5):887-90. http://dx.doi.org/10.1590/S0034-89102009005000051. PMid:19738995.

7. Classen DC, Resar R, Griffin F, Federico F, Frankel T, Kimmel N, Whittington JC, Frankel A, Seger A, James BC. 'Global trigger tool' shows that adverse events in hospitals maybe ten times greater than previously measured. Health Aff (Millwood). 2011;30(4):581-9. http://dx.doi.org/10.1377/hlthaff.2011.0190. PMid:21471476.

8. Varallo FR, Dagli-Hernandez C, Pagotto C, de Nadai TR, Herdeiro MT, Carvalho Mastroianni P. Confounding variables and the performance of triggers in detecting unreported adverse drug reactions. Clin Ther. 2017;39(4):686-96. http://dx.doi.org/10.1016/j.clinthera.2016.11.005. PMid:27913030. 
9. Beccari M, Meaney C. Clinical utility of patiromer, sodium zirconium cyclosilicate, and sodium polystyrene sulfonate for the treatment of hyperkalemia: an evidence-based review. Core Evid. 2017;12:11-24. http://dx.doi.org/10.2147/CE.S129555. PMid:28356904.

10. Nassif ME, Kosiborod M. New frontiers for management of hyperkalaemia: the emergence of novel agents. Eur Heart J. 2019;21(Suppl A):A34-40. http://dx.doi.org/10.1093/eurheartj/suy036. PMid:30837803.

11. Palaka E, Leonard S, Buchanan-Hughes A, Bobrowska A, Langford B, Grandy S. Evidence in support of hyperkalaemia management strategies: A systematic literature review. Int J Clin Pract. 2018;72(2):7. http://dx.doi.org/10.1111/ijcp.13052. PMid:29381246.

12. Varallo FR, Trombotto V, Lucchetta RC, Mastroianni PC. Efficacy and safety of the pharmacotherapy used in the management of hyperkalemia: a systematic review. Pharm Pract (Granada). 2019;17(1):1361. http://dx.doi.org/10.18549/PharmPract.2019.1.1361. PMid:31015873.

13. Ben Salem C, et al. Drug-Induced Hyperkalemia. Drug Safety. 2014;37:677-692. http://dx.doi.org/10.1007/s40264-014-0196-1.

14. Varallo FR, Lucchetta RC, Forgerini M, Mastroianni PC. What would be a trigger tool with better performance for detecting drug-induced hyperkalemia? Sao Paulo Med J. 2019;137(4):386-7. http://dx.doi.org/10.1590/1516-3180.2019.0081050719. PMid:31531593.

15. Neto OMV, Neto MM. Distúrbios do equilíbrio hidroeletrolítico. Medicina (B Aires). 2003;36:325-37.

16. Peacock WF, et al. Real World Evidence for Treatment of Hyperkalemia in the Emergency Department (REVEAL-ED): A multicenter, prospective, observational study. J Emerg Med. 2018;55(6):741-50. http://dx.doi.org/10.1016/j.jemermed.2018.09.007. PMid:30391144.

17. Dépret F, Peacock WF, Liu KD, Rafique Z, Rossignol P, Legrand M. Management of hyperkalemia in the acutely ill patient. Ann Intensive Care. 2019;9(1):32. http://dx.doi.org/10.1186/s13613-019-05098. PMid:30820692.

18. Nyirenda M, Tang Jl, Padfield PL, Seckl JR. Hyperkalaemia. BMJ. 2009;339(1):b4114. http://dx.doi.org/10.1136/bmj.b4114. PMid:19854840.

19. Sterns RH, Grieff M, Bernstein PL. Treatment of hyperkalemia: something old, something new. Kidney Int. 2016;89(3):546-54. http://dx.doi.org/10.1016/j.kint.2015.11.018. PMid:26880451.

20. Rochon P, Gurwitz J. Drug therapy. Lancet. 1995;346(8966):32-6. http://dx.doi.org/10.1016/S01406736(95)92656-9. PMid:7603146.

21. McCarthy LM, Visentin JD, Rochon PA. Assessing the scope and appropriateness of prescribing cascades. J Am Geriatr Soc. 2019;67(5):1023-6. http://dx.doi.org/10.1111/jgs.15800. PMid:30747997.

22. Mushiyakh Y, Dangaria H, Qavi S, Ali N, Pannone J, Tompkins D. Treatment and pathogenesis of acute hyperkalemia. J Community Hosp Intern Med Perspect. 2012;1(4):7372. http://dx.doi.org/10.3402/jchimp.v1i4.7372. PMid:23882341.

23. World Health Organization. Medication safety in polypharmacy. Geneva, Switzerland: World Health Organization. 2019. p. 11-3.

24. World Health Organization. International drug monitoring: the role of national centres. Vol. 498. Report of a WHO meeting. Geneva, Switzerland: World Health Organization. 1972. p. 1-25.

25. World Health Organization. The use of the WHO-UMC system for standardized case causality assessment. Uppsala Uppsala Monit Cent. 2005; 2-7.

26. Becker S. Contemporary view of medication-related harm. A New Paradigm. 2004;13:306-14.

\section{Authors' contributions}

MBV carried out data collection, findings tabulation and contributed to write the manuscript; MF and TRD performed statistical analysis, contributed to write the results and discussion of the manuscript; FRV and PCV were responsible by study design, contributed for data collection, tabulation, and discussion of the article. 